\title{
Against Natural Kind Eliminativism
}

\author{
Stijn Conix ${ }^{1} \&$ Pei-Shan $\mathrm{Chi}^{2}$ \\ ${ }^{1}$ Centre for Logic and Philosophy of Science, KU Leuven, stijn.conix@kuleuven.be \\ ${ }^{2}$ ECOOM - Centre for Research and Development Monitoring, KU Leuven
}

\section{$27 / 2 / 2020$, pre-print accepted for publication in Synthese}

\begin{abstract}
It has recently been argued that the concept of natural kinds should be eliminated because it does not play a productive theoretical role and even harms philosophical research on scientific classification. We argue that this justification for eliminativism fails because the notion of 'natural kinds' plays another epistemic role in philosophical research, namely, it enables fruitful investigation into nonarbitrary classification. It does this in two ways: first, by providing a fruitful investigative entry into scientific classification; and second - as is supported by bibliometric evidence - by tying together a research community devoted to non-arbitrary classification. The question of eliminativism then requires weighing off the benefits of retaining the concept against its harms. We argue that the progressive state of philosophical work on natural kinds tips this balance in favour of retaining the concept.
\end{abstract}

\section{Introduction: pluralism and eliminativism}

It is common for scientific concepts to fragment into multiple more precise concepts. Typically, this occurs when the referent turns out to be heterogeneous or when the concept plays multiple theoretical roles. For example, the species concept has been split into over thirty different concepts, the gene-concept is used in at least three distinct ways, and even the term 'concept' itself has been split up into smaller concepts.

This phenomenon has generated much interest amongst philosophers, who generally adopt one of two positions: eliminativism or pluralism. The former option involves getting rid of the general concept and using the precise concepts instead. Examples include Ereshefsky (1992) about species, Machery (2009) about concepts and Griffiths (2002) about innateness. The latter option too involves using the precise concepts, but without eliminating the general concept. The precise concepts are then defined as sub-concepts of the same broader concept. Examples include Brigandt (2003) about species, Hampton (2010) about concepts and Cowie (2009) about innateness.

This raises the question of how to choose between eliminativism and pluralism for fragmented concepts. While there is no agreement about which option is best for any of the concepts mentioned above, there is broad agreement that what matters for this choice is the epistemic usefulness of the concept. For example, Ereshefsky (1992, p. 680) defends species eliminativism by arguing that the term is not useful for communication among biologists while Brigandt (2003, p. 1306) argues against eliminativism by showing that 'the species concept is a useful and theoretically important concept in biology'. There is, in other words, a broad consensus that fragmented scientific concepts should be 
eliminated if they do not contribute to attaining the epistemic aims of the field in which they figure (see also Taylor and Vickers 2017). Conversely, fragmented concepts should be retained alongside their precise sub-concepts if they play a valuable epistemic role. Note that it does not matter on this pragmatic view whether the referent of the concept is a homogeneous category: productive concepts should be retained even if they collect entities as heterogeneous as, say, classically conceived genes and genes conceived at the molecular level (Waters 2006).

This paper will apply this pragmatic framework, which stems from debates about scientific concepts, to the philosophical concept of 'natural kinds'. Like species and genes, this concept has been the subject of eliminativist claims on the basis of its fragmentation and its seeming uselessness (Hacking 2007; Ludwig 2018). Arguing against such eliminativism, we will highlight a valuable and overlooked epistemic role that the concept plays in philosophy. Our conclusion will be that this role justifies retaining the concept. To do this, the paper will proceed as follows. Section 2 discusses arguments for natural kind eliminativism. Section 3 discusses the aims of philosophical research into natural kinds, and sections 4, 5 and 6 highlight an overlooked epistemic role of 'natural kinds' that contributes to attaining these aims. Borrowing a notion from Brigandt (2003, p. 1308), we call this role 'investigative'. Section 7 then argues that this investigative role justifies retaining the notion of 'natural kind' in philosophy. Section 8 concludes the paper.

\section{Natural kind eliminativism}

Theorizing about natural kinds has a long history in philosophy, starting with Mill, Whewell and even Locke (Boyd 1991; Hacking 1991, 2007). Today, natural kinds are typically understood as categories that reflect real divisions in the world, or, to use a time-worn metaphor, carve nature at its joints. They are opposed to artificial or non-natural kinds, which are thought to reflect the preferences and aims of their users rather than the structure of the world. This distinction between natural and artificial kinds has been put to work in philosophy to make sense of classificatory practices in science. In this context, a wide variety of theories of natural kinds have been put forward over the past decades (e.g. Boyd 1991; Franklin-Hall 2015; Khalidi 2015; Magnus 2012; Slater 2014).

Despite the lively debate about natural kinds, David Ludwig (2018) and lan Hacking (2007) have called for eliminating the concept. Their arguments for this start from a double heterogeneity. First, they point out that the natural kind concept is used to refer to a variety of kinds that do not have one thing in common. Hacking makes this point by exposing the heterogeneity of paradigmatic examples of natural kinds. These include a group of organisms connected by ancestry and descent (tigers), a metal with a particular atomic structure (gold), the transfer of energy from a thermodynamic system (heat), and a family of immune-mediated diseases (multiple sclerosis). 'The sheer heterogeneity of the paradigms for natural kinds invites scepticism' (Hacking 2007, p. 207). Ludwig makes the same point by highlighting the variety of non-arbitrary ethnobiological kinds. Among the seven kinds of nonarbitrary ethnobiological kinds Ludwig (2018) discusses are 'mind-independent convergent kinds' (35), which are kinds that reoccur in different cultures simply because they latch on to similar features in the world; and 'practice dependent kinds' (37), which are kinds shaped by empirical properties and cultural practices that engage with these properties. Ludwig's point is that while all these kinds are non-arbitrary, they are so in interestingly different ways. It follows, as Hacking $(2007,203)$ puts it, that 'there is no such thing as a natural kind'.

This heterogeneity of kinds lies at the basis of a second heterogeneity, namely, of theories of natural kinds. Hacking $(2007,203)$ merely refers to 'the sheer proliferation of incompatible views', 'a slew of distinct analyses' (203) and a lot of 'mutually incommensurable theories'(229). Ludwig discusses some of these theories in more detail, and shows how different views on natural kinds can account for 
different ethnobiological kinds. For example, Franklin-Hall's (2015) 'categorical bottle-neck account' of natural kinds, which defines them as the categories that would be useful to a wide range of actors, is useful for understanding the convergence between classifications of different cultures. However, Franklin-Hall's view on natural kinds cannot account for practice-dependent kinds, as they are tied to the interaction between empirical properties and particular cultural practices. For this, we could turn to Slater's (2014) 'Stable Property Cluster' account, as it explains the success of natural kinds by their relation to stable clusters of properties in the world. Other theories, such as Khalidi's (2015) or Magnus' (2012), are useful for understanding yet other kinds of kinds. The point is that while all these theories are useful for understanding some kinds, there is no single theory that can account for all of them.

In short, there are many different kinds of kinds, and there is no single theory of natural kinds that can account for all of them. Ludwig and Hacking draw the same conclusions from this double heterogeneity: the concept of natural kinds does not play a useful theoretical role in philosophy. Given that there is nothing common to all natural kinds, there is no general property that the concept refers to. Moreover, there are multiple precise theories of natural kinds that explain different aspects of natural kinds: if our research concerns mind-independent convergent kinds, Franklin-Hall's bottleneck account is best; if our research concerns practice-dependent kinds, Slater's Stable Property Cluster view may be more helpful; yet other kinds would require yet other theories or combinations of theories. To make sense of classificatory practices, then, we can simply use all these precise theories instead of the general concept of natural kinds. This leaves no role for the general concept of natural kinds. Now that we have this 'multi-dimensional framework of non-arbitrary classification' (Ludwig 2018,40 ) to do the theoretical work, the general concept adds 'not one jot of content' (Hacking 2007, 231).

Assuming the pragmatic framework of this paper, the theoretical uselessness of the natural kind concept seems sufficient to warrant elimination. However, Ludwig and Hacking add further reasons: not only is the concept useless, it is also harmful. According to Ludwig (2018, 45ff), this is because attempts at formulating a general account of natural kinds tend to privilege one aspect of non-arbitrary classification over others. Hacking $(2007,228-229)$ claims that current theories of natural kinds constitute the 'scholastic twilight' of natural kinds debates, and suggests an even harsher conclusion: philosophical work on natural kinds is involved with 'an inbred set of degenerating problems that have increasingly little to do with issues that arise in a larger context' (229). To the extent that these debates do try to engage with legitimate questions, the answers are confused by countless semantic and metaphysical connotations that have become entangled with the concept over two centuries of philosophical investigation. Given that the natural kind concept plays no theoretical role and harms philosophical research on classification, Ludwig's and Hacking's arguments have a straightforward conclusion:

Take any discussion that helps advance our understanding of nature or any science. Delete every mention of natural kinds. I conjecture that as a result the work will be simplified, clarified, and be a greater contribution to understanding or knowledge. Try it. (Hacking 2007, 229)

\section{The aims of research and the natural kind phenomena}

The remainder of this paper will challenge Ludwig's and Hackings' position. Because their eliminativism is based on the uselessness of the concept, it is helpful to start from the aims of natural kind research. Because much of the natural kind debate over the past two decades has taken place in philosophy of science, we will, like Ludwig, focus on the aims of the concept in this subfield. While this inevitably 
sketches an incomplete picture of the aims of natural kind debates in philosophy, it will be sufficient to challenge eliminativism.

At first sight, recent contributions to the debate seem to have little in common. Some, like Dupré (1993), are interested in pluralism and the metaphysics of kinds, while others, like Franklin-Hall (2015), are interested in the epistemology of kinds. Another research tradition, exemplified by Boyd (1991), is mainly interested in the relation between scientific language and the world. Yet others are interested in the kinds of a particular discipline (Havstad 2018) or the way kinds come into being (Kendig 2016). However, there is a broad aim that connects these heterogeneous contributions: they all aim to understand the functioning of kinds in science. More precisely, they try to clarify the role kinds play in science and how they can play this role with the incredible success we observe. ${ }^{1}$

We argue that the role of the natural kind concept is directly connected to this general aim of understanding scientific kinds. More precisely, we argue that philosophers of science use it to refer to a phenomenon of interest in scientific classificatory practices. MacLeod and Reydon (2013, p. 90) point to this phenomenon when they write that 'at a very basic level scientists, but also philosophers, share a need to distinguish between natural-with connotations such as objective, existing "out there" in the world, real, stable, unique, etc. - and artificial ways of grouping things together'. That is, scientists in a wide variety of disciplines seem to consider some kinds reflections of the world, and other kinds merely pragmatic tools. For example, it is a popular opinion among taxonomists that species as units of evolution are real in a sense that higher taxa are not (Wiley 1981). Similarly, chemists generally believe that the periodic table reflects the world in a way that the classification of enzymes does not. Understanding classification in science, as philosophers aim to do, requires making sense of this 'natural kind phenomenon'.

Two clarifications concerning this phenomenon are in place here. First, the term 'phenomenon' is a two-place predicate: it concerns a set of similarities that appears to observers, namely, philosophers of science. By consequence, the term 'phenomenon' here does not refer to the nature of the classificatory practices that philosophers are investigating. Instead, it consists of an observed pattern in classificatory practices across different branches of science. The 'nature' of the phenomenon is precisely what philosophers aim to uncover in investigating it. It may turn out that the observed patterns are unified in some more fundamental and interesting ways, but it may also be that this is not the case.

Second, and related to this, even if different parts of the phenomenon (e.g. classificatory practices in different fields) appear similar in some way, they are clearly very diverse too. For example, classifications considered natural in biology are often based on causal history, while natural classifications in chemistry and psychology are often based on causal mechanisms. Moreover, the natural kind phenomenon includes things as diverse as the linguistic practices of scientists, their use of categories for inferences and representation, and their implicit ontologies. Hence, it is better to speak of a cluster of phenomena rather than a single phenomenon. ${ }^{2}$ Still, the point is that, despite this diversity, this cluster of phenomena appears unified in a way that invites further investigation: the kinds that scientists consider natural are typically useful for explanation, prediction and understanding; they typically connect a wide range of properties, and often because they capture causal mechanisms; and the terms figuring in scientific laws are often considered natural kinds. Thus, understanding the

\footnotetext{
${ }^{1}$ See Bursten (2018, pp. 4-9) for a more extensive defence of this claim.

${ }^{2}$ We want to thank an anonymous reviewer for pointing this out to us.
} 
natural kind phenomena seems particularly important if we want to understand classificatory practices in science.

Connecting the general concept of natural kinds to this phenomenon-to-be-clarified provides background to Ludwig's criticism: the concept is imprecise simply because it refers to an observed cluster of phenomena. As philosophers' understanding of what lies behind this cluster is incomplete, the concept used to refer to it should be expected to be vague and heterogeneous. Of course, this does not justify retaining the concept in our philosophical vocabulary, as it does not imply that the concept also plays a fruitful role in shedding light on classificatory practices. Indeed, this is precisely what Ludwig raises doubts about: Several decades of philosophical research have revealed that the observed distinction between natural and non-natural kinds comprises different kinds of kinds, and there is no single theory of natural kinds that can account for all of these. This suggests that what may have seemed a tightly unified cluster of phenomena actually consists of various distinct patterns that are better studied with more precise concepts.

To reject this argument, then, it needs to be shown that despite its imprecise character, the concept of natural kind contributes epistemically to our understanding of scientific classification. To do this, section 4 will highlight one useful epistemic role it plays, which we call 'investigative', and distinguish it from the theoretical role that Hacking and Ludwig focus on. Thus, while we do not challenge the eliminativists' claim that the concept is not theoretically useful, we deny that this justifies eliminativism, since it plays another epistemically useful role.

\section{Investigative kinds}

The previous section argued that the aim of natural kind debates in philosophy of science is to deepen our understanding of scientific classification. In the remainder of the paper, we will argue that the natural kind concept plays a productive epistemic role in attaining this aim by enabling philosophical investigation. Borrowing - and slightly repurposing - a term that Brigandt (2003) introduced in debates about species eliminativism, we call the natural kind concept an investigative concept.

Broadly put, we argue that the natural kind concept is epistemically productive in philosophy because it facilitates research into scientific classification, and, more precisely, the observed distinction between natural and non-natural kinds. We saw that this distinction seems to lie at the intersection of various interesting observed patterns in scientific classification. Engaging with the natural kind concept and pursuing the questions it suggests constitute a way of shedding light on this distinction and the patterns related to it. This way, the natural kind concept provides an investigative entry into classificatory practices in science. Importantly, the concept can play this role even if we lack a fullfledged theoretical account of the distinction or if such an account is impossible. Macleod and Reydon $(2013$, p. 96) propose a similar a-theoretical, investigative role for the concept when they write that 'the job of a natural kind concept would never be to provide conceptual unity across disciplines but rather to provide a platform for exploring important and significant differences across an essentially disunified science'.

In short, the natural kind concept enables the study of an observed cluster of phenomena. Using the imprecise concept that refers to this cluster gives us a way in for investigation that may ultimately lead to a theoretical account, or, as Ludwig argues, multiple accounts. Cowie $(2009$, p. 96$)$ attributes a very similar role to the scientific concept of innateness:

[Y]ou can't investigate something if you don't have a way of thinking about it. The concept of innateness, I contend, enables us to think about developmental phenomena that we don't yet 
fully comprehend. Throw that concept away, and we lose that ability; lose the ability to think about those phenomena, and you lose the ability to investigate them.

Similarly, the concept of natural kind gives philosophers of science an investigative entry to engage with classificatory practices in science.

As the quote on innateness already suggests, such investigative concepts play a prominent role in science too. To understand the role of the natural kind concept in philosophy, it is useful to look at some investigative scientific concepts in more detail. One salient example of such an imprecise but fruitful investigative notion is the gene-concept. Some argue that this concept is harmful for biology because it promotes a gene-centric view that unwarrantedly privileges genes over other causal factors in development. Waters (2006, p. 210) argues that this criticism misconstrues the role of the geneconcept, which is often not theoretical but rather serves 'the interest to investigate'. He argues that the gene-concept figures prominently in biological research not because of its role in a theoretical account of development, but because it provides a productive investigative entry into processes of interest. For example, Waters argues that classical genetics had no overarching theory of development that placed genes in a privileged causal role. Instead, classical geneticists recognised that genes, typically identified by their phenotypic effects, were causally involved in a wide range of processes. By identifying mutations that interfered with these processes, they could intervene on these genes and manipulate the processes. Instead of developing a grand theory, these biologists used genes as a fruitful entry point to investigate and manipulate processes of interest. In short, Waters (2006, p. 210) writes, 'genes are at the centre of attention because of their investigative utility, not because of their alleged explanatory power'.

Through these investigations, it has become clear that the general gene-concept hosts a diversity of fine-grained notions, each of which refers to different things with different theoretical roles. However, this diversity does not stop the notion from playing a fruitful role. Indeed, as Cowie (2009, p. 92) points out, it may even contribute to its epistemic success:

Many new discoveries and techniques, not to mention better concepts, were born of the jostling between the apparently incompatible notions of gene-as-replicator, gene-as-protein, gene-as-locus-of-mutation, gene-as-producer-of-phenotypical-characters, etc. And while the counterfactuals are, of course, speculative, it is hard not to believe that had any of these been jettisoned prematurely, the nature of the relations between them would not have been clarified, but rather obscured further, to the likely detriment of both biological research and our understanding of the world.

Further examples of fruitful investigative concepts in science are easy to come by. ${ }^{3}$ For example, in response to Machery's concept-eliminativism, Hampton points out that even if the concept is polysemous, it lies at the basis of much productive psychological research. He (Hampton 2010, p. 212; see also Strohminger and Moore 2010) argues that the concept is necessary as a 'framework for integration', and shows how it plays a crucial role in exploring the connections between different kinds of concepts. Similarly, Brigandt (2003) shows how the general species concept plays a productive investigative role in biology, despite being split up into more than thirty concepts.

The point of these examples is that many productive scientific concepts are too vague to figure in precise theories. This conceptual confusion does not stop them from playing a fruitful investigative

\footnotetext{
${ }^{3}$ There are many more examples if we consider scientific products beyond concepts. Most prominently, models too have been argued to sometimes play a heuristic rather than a theoretical role (e.g. Frigg and Hunter 2010).
} 
role. As Cowie (2009, p. 92) puts it, 'good things come from "bad" concepts'. These concepts give us an investigative angle to tackle phenomena that we do not fully comprehend. Eliminating them comes at the cost of losing the ability to investigate these phenomena, and history shows that such investigations can be highly productive.

Similarly, we argue that the prime role of the natural kind concept - and thus the prime justification for retaining it - does not lie in explaining particular instances of non-arbitrary classification, but in the way it enables investigation into the natural kind-phenomena in science. We argue that it does this in two ways: first, the concept of natural kinds directly determines the content of research by raising questions on the connections between different aspects of the natural kind phenomena and by motivating research on general patterns in these phenomena; and second, the phrase 'natural kind' indirectly enables fruitful research because it figures as a platform that connects researchers across different research fields. We discuss these two investigative roles in the next two sections.

\section{The investigative role of the natural kind concept}

The previous section introduced the idea of the natural kind concept as an investigative kind, and discussed how various scientific concepts play a productive investigative role in science. This section shows that the natural kind concept plays a similar investigative role in philosophy. To do this, we highlight two ways in which the concept directly facilitates investigation of the natural kind phenomena: research on connections between theories of natural kinds, and research that makes general claims about natural kinds.

The first kind of research on classificatory practices spurred by the natural kind concept concerns the relations between competing accounts of natural kinds. Consider Boyd's (1991) causal cluster-view of natural kinds and Slater's (2014) non-causal cluster-view. Both define natural kinds as clusters of properties, but only the former requires that this clustering is due to a set of causal mechanisms. Eliminativists argue that both views highlight different but interesting relations between non-arbitrary kinds and the world: some scientific kinds are causal, and some are non-causal. However, this eliminativist argument glosses over the fact that there is substantial overlap between causal and noncausal kinds. Bacterial species, for example, are often characterized on the basis of genetic similarity (non-causal) and phylogeny, i.e. the aetiology of their genome or characters (causal). And there are more interesting relations between causal and non-causal kinds. For example, non-causal kinds often serve as targets of scientific investigation until their causal nature is understood (Hacking 1991, pp. 119-120). Because of this, kinds that are defined on non-causal grounds later often get redefined on causal grounds, while the converse is rare.

We are not the first to emphasize interesting patterns involving different kinds of kinds. For example, Slater (2014) shows how his account of 'natural kindness' encompasses various other views on natural kinds. Similarly, Lemeire (2018) distinguishes and argues against what he calls 'epistemology-only' theories of natural kinds, which include Franklin-Hall's (2015) and Ereshefsky and Reydon's (2014) views among others. It is clear that the role of the natural kind concept in such research is not theoretical. Clarifying the overlap between different accounts of natural kinds does not require us to define natural kinds or restrict the usage of that concept to a particular subset of scientific kinds. Indeed, the theoretical work in Lemeire's and Slater's work is done by precise concepts of natural kinds. The general concept of natural kinds then serves as the framework within which different kinds of natural kinds are conceptualised as part of the same cluster of phenomena. This allows us to investigate the relations between the different precise concepts. On their own, these concepts pick out interesting features of scientific classification but cannot capture the patterns that connect them. 
Research spurred by the general concept of natural kinds naturally leads to investigating these patterns and thus reveals interesting features of classificatory practices.

A second investigative role of the natural kind concept is apparent in general claims about natural kinds. Such general claims shed light on the observed cluster of phenomena without thereby constructing a general theoretical account of naturalness. These claims do this by pointing to interesting patterns in the cluster that have not been clarified by any of the precise natural kind concepts. Two recent examples will serve to illustrate this. First, consider Love's (2009) and Macleod's (2013) claims that debates about classification in philosophy of science have focused too much on the role of natural kinds in supporting generalizations. They argue that this focus, often paired with particular attention for the metaphysics of kinds, has gone at the expense of attention for other epistemic strategies or tactics that involve natural kinds, such as modelling and experimentation. In other words, these authors make a general claim about the diversity of roles played by kinds subsumed under the natural kind phenomena. Moreover, this is a productive claim as it uncovers a shortcoming of our current understanding of these phenomena, and suggests a way forward for investigating them. Second, Julia Bursten (2018) discusses chemical kinds and nanomaterials and points out that philosophers of science have overlooked the importance of scale for scientific classification. Different fields of science and different interests within those fields require classification at different scales, and consequently consider different properties or structures relevant for classification. Taking scale into account is thus crucial for understanding differences between classifications in different research settings.

Bursten, Love and MacLeod all make general claims about the cluster of natural kind phenomena that deepen our insight without directly providing a theoretical account of natural kinds. Indeed, they all use the natural kind concept in a way that is not harmed by its imprecise nature: even if it is unclear what precisely counts as a natural kind and why, it is clear that the scale of description matters and that natural kinds play various epistemic roles. Instead of figuring as a precise description of a particular set of kinds, the notion of natural kinds denotes the observed cluster of phenomena that is the target of these philosophers' investigations. While the outcomes of these investigations may ultimately contribute to theoretical accounts of kinds, the concept itself did not contribute to this theory apart from facilitating investigation.

\section{The social role of the phrase 'natural kind'}

The previous section argued that the natural kind concept facilitates philosophical research into scientific classification by providing an entry for research. This subsection argues that in addition to this direct investigative role of the concept, the linguistic phrase 'natural kind' enables philosophical investigation in another way. This role is social: the phrase facilitates research by tying together a research community and research tradition. As eliminating natural kinds from philosophy would get rid of this phrase, eliminativism comes at the cost of losing the social role of the phrase too.

This social role is prima facie clear to anyone familiar with the recent debate on natural kinds in philosophy. Since 2010, there have been thirteen workshops or conferences, six PSA and EPSA sessions, various edited volumes (e.g. Campbell et al. 2011; Kendig 2016), and special journal issues (e.g. Macleod and Reydon 2013b; McFarland, 2018) dedicated to natural kinds. In addition, new journal papers (e.g. Bursten 2018; Lemeire 2018) and monographs (e.g. Khalidi 2013; Magnus 2012) about natural kinds are published on a regular basis. Diverse as these contributions may be, their association to the phrase makes them into a connected body of work that any philosopher of science working on scientific classification will start from and engage with. 
To investigate the role of the phrase 'natural kind' in tying together this research community, we use bibliometric methods. Subsection 6.1 shows that the phrase ties together a research community within philosophy, and subsection 6.2 shows that the phrase also ties this philosophical community to researchers in other fields. All tests discussed in these sections are conducted with bibliographic items downloaded in the first two weeks of June 2019 from the online version of the Web of Science Core Collection (WoS) of Clarivate Analytics, including the Science Citation Index Expanded (SCIE), the Social Sciences Citation Index (SSCl) and the Arts \& Humanities Citation Index (A\&HCI). As we are interested in the role of the phrase 'natural kind', we did not search for synonyms like 'scientific kinds' or 'scientific categories'. We limited the volume year to 2001-2017 to have a long-term analysis and ensure that all publications have at least a three-year citation accumulation period. Because philosophers publish mainly articles and book reviews in the WoS indexed journals, ${ }^{4}$ we initially collected both document types. However, as most book reviews in the downloaded data cite only one reference (i.e. the reviewed book), we limit the analyses to articles.

\subsection{A social role in philosophy}

We argue that research on scientific classification benefits from a well-connected philosophical research community, and that the phrase 'natural kind' plays an important role in integrating this community. The epistemic benefits of such a well-connected community are easy to see: exposure to the findings and ideas of peers allows researchers to build on each other's work, criticism from peers can expose false beliefs (Betz 2012), and a diversity of points of view can help exposing non-trivial background assumptions (Longino 1990). Others point to the epistemic benefits of collaboration (Thagard 2006; Wray 2002), which are clearly reflected in citation numbers (Larivière, Gingras, et al. 2015; Wuchty et al. 2007), and to the fact that successful fields tend to evolve from multiple disconnected clusters to a single, well-connected network of researchers (Bettencourt et al. 2009).

In this context, it is worth noting that there is also some model-based work in social epistemology that suggests that sometimes well-connected communities are less reliable than communities with decreased connectivity (Zollman 2007, 2010). One reason for this so-called 'Zollman-effect' is that both true and false beliefs can spread easily and fast in well-connected communities. However, we claim that in the case of philosophical research on scientific classification, a well-connected community is epistemically better than one with fewer connections between the members. This is because the Zollman-effect is strongly context-dependent, and only occurs in very specific circumstances (Borg et al. 2018; Frey and Šešelja 2019). Rosenstock et al. (2017) show that increased connectivity increases the reliability of scientific communities except if learning is difficult, i.e. when it is difficult to distinguish between two competing theories. In addition, Frey and Seselja (2019) show that even when learning is difficult, the Zollman-effect only occurs when researchers are not cautious in deciding which theory to pursue, and when they do not have difficulty in aggregating various epistemic standards relevant for theory choice. While it is unclear whether it is easy to distinguish good from bad theories about scientific classification, the other two criteria do seem to apply here: philosophers often stick to their preferred position even when new arguments against them are raised (i.e. they are very cautious), and it is often the case that there is no single philosophical theory that is preferable by all relevant epistemic standards. It seems likely, then, that the natural kinds-debate falls outside of the particular circumstances in which the Zollman-effect can be expected to occur. This means that increased connectivity is epistemically beneficial.

\footnotetext{
${ }^{4}$ For example, 53\% of 185,681 WoS-indexed papers published between 2001 and 2017 in the WoS subject category 'Philosophy' are articles, and $38 \%$ of them are book reviews.
} 
To test the hypothesis that the phrase 'natural kind' ties together a research community, we ran a bibliographic coupling (BC) analysis of recent papers on natural kinds. $\mathrm{BC}$ is a measure of the similarity of two documents based on their citing common references (Kessler 1963). We used this measure rather than co-citation because citation numbers in philosophy are very low, especially for recent papers, ${ }^{5}$ and the latter requires a set of fairly well-cited papers and a sufficiently long citation window (Glänzel and Czerwon 1996). More importantly, BC is a good method for placing papers in their social context because researchers' selection of references are importantly influenced by this context, e.g. by which texts were read in graduate school, with whom the author collaborates or interacts, and which papers or journals are considered canonical by the community (Weingart 2015, pp. 203-204). ${ }^{6}$ Thus, the BC map of natural kind papers can be expected to be a good indicator of the extent to which the authors of these papers are part of a well-integrated research community.

To obtain a data set of publications on natural kinds in philosophy, we searched for natural kind related papers in the five top philosophy journals (Philosophical Review, Mind, Nous, Philosophy \& Phenomenological Research) according to a recent survey, ${ }^{7}$ five key journals in philosophy of science (Philosophy of Science, British Journal for Philosophy of Science, Erkenntnis, Synthese, Studies in History and Philosophy of Science A) according to a citation analysis by Wray (2010), and one journal (Journal of Philosophy) that was ranked highly in both. The search in WoS yielded 96 articles published between 2001 - 2017 which in total had 4,113 references. ${ }^{8}$ After data cleaning and generating the network in BibExcel, ${ }^{9}$ the bibliographic coupling analysis of the 96 articles was visualised using VOSviewer 1.6.9. ${ }^{10}$

While the analysis distinguishes three clusters, figure 1 unambiguously shows that the natural kind papers form a well-integrated author network. Given that these papers were selected on the basis of having the term 'natural kind' in either keywords, title, or abstract, this confirms our hypothesis that the phrase 'natural kind' ties together a well-connected research community. For comparison, we constructed the equivalent BC map of articles about 'objectivity'. Since this concept too has been argued to be vague, not theoretically useful, and ready for elimination (e.g. Ludwig 2017), it forms an interesting contrast reference for the level of integration of the natural kind community. ${ }^{11}$ The search for papers relating to objectivity in WoS yielded 62 papers between 2001-2017, ${ }^{12}$ which is comparable in size to the set of natural kind papers. Figure 2 shows that papers on objectivity are distributed between multiple, ill-connected clusters with some isolated author clusters. This forms a clear contrast with the tightly connected network of papers representing research on natural kinds.

\footnotetext{
${ }^{5}$ For example, the average citation rate of the 8,056 articles published in 2017 under the WoS subject category 'Philosophy' is 0.97, according to a search on 22 August, 2019.

${ }^{6}$ In other fields of research, social networks are often investigated by means of collaborations between scientists. However, as collaboration practices in philosophy are very different from those in the fields of science for which these methods were developed, we did not use them here.

${ }^{7}$ https://leiterreports.typepad.com/blog/2018/11/best-general-journals-of-philosophy-2018.html

${ }^{8}$ See supplementary material, 'term 1 ' for the search term.

${ }^{9} \mathrm{BibExcel}$ is a commonly-used tool-box for analysing bibliographic data, available at https://homepage.univie.ac.at/juan.gorraiz/bibexcel/.

${ }^{10}$ VOSviewer is a software tool for creating maps based on network data, developed by the CWTS group at Leiden University. https://www.vosviewer.com/

${ }^{11}$ Ideally, we would compare the natural kind debate to debates on the same topic had the notion of natural kind never been used. Because this counterfactual comparison is not possible, we have to make do with objectivity (in section 6.1) and 'laws of nature' (in section 6.2).

${ }^{12}$ See supplementary material, 'term 2 ' for the search term.
} 


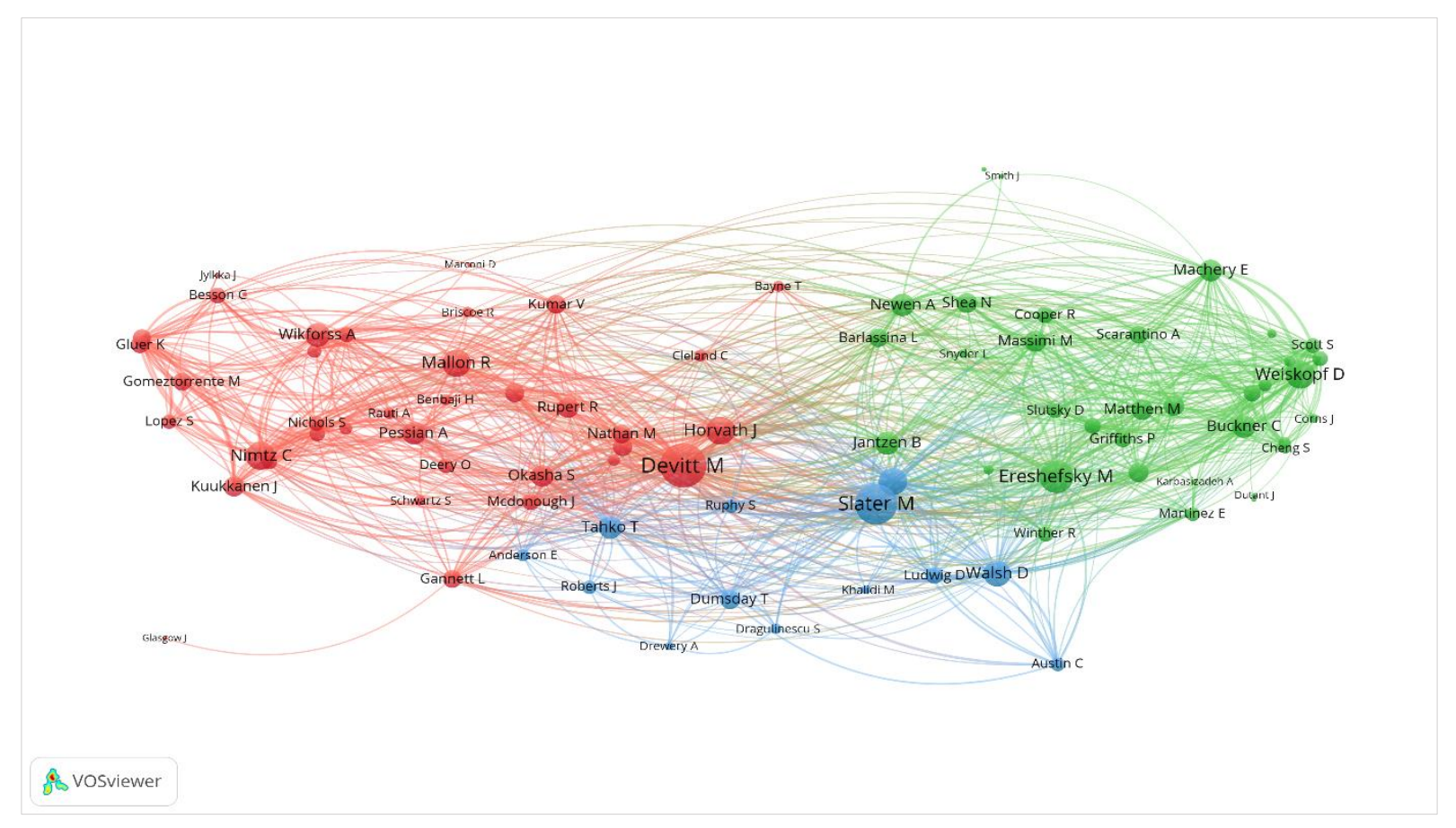

Figure 1. The bibliographic coupling network of 86 authors from the papers on natural kinds in philosophy (2001-2017). Clustering resolution is 0.9 forming three clusters.

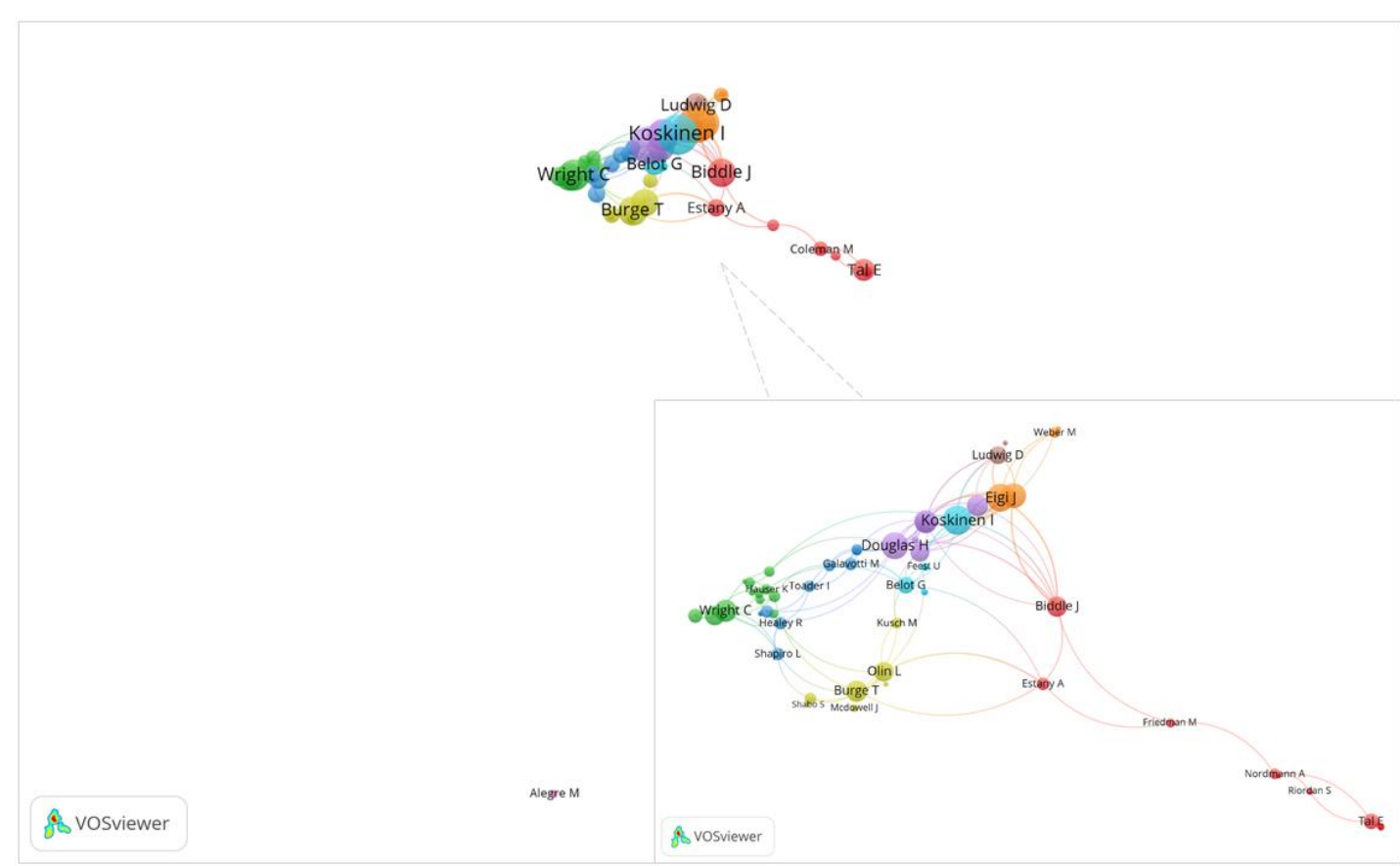

Figure 2. The bibliographic coupling network of 63 authors from the papers on objectivity in philosophy (2001-2017). Clustering resolution is 0.9 forming nine clusters. A cluster of two authors (Alegre, $M$ and Votsis, I) with one reference link between is isolated in the network.

\subsection{A bridge between philosophy and other fields}

The previous subsection showed that researchers working on natural kinds form a well-connected community. Even if this is often an indicator of successful fields of research, one may worry that even 
without the Zollman-effect this is not always a good sign: cottage industries of papers on a single, often esoteric topic - unfortunately a phenomenon familiar to many philosophers - are arguably not epistemically healthy but are likely to be closely connected. Higgins and Dyschkant (2014), for example, consider much work in analytic ontology problematic because it forms such a highly isolated but internally tightly connected cluster of research. Thus, a well-connected cluster is only the sign of an epistemically productive community if it goes together with connections to other fields of research too. There are also independent reasons to believe that such connections to other fields indicate the health of a research programme: bibliometric research shows that research that builds on work from multiple fields is significantly more innovative and has more impact (as measured by citations) than mono-disciplinary research (Larivière, Haustein, et al. 2015; Wang et al. 2017). We will assume, then, that a philosophical research programme is more likely to be productive if it is well-connected to other fields of research. Thus, a second way in which the phrase 'natural kind' could play an epistemically productive social role is by connecting philosophical research to other scientific fields.

The phrase 'natural kinds' is commonly used by philosophers to refer to the kinds that other scientists recognise as legitimate scientific categories. Hence, it would not be surprising if there are nonphilosophers among the community of researchers that discuss natural kinds. To test whether this is the case, we constructed a BC map of the 539 articles (adding up to a total of 26,493 references) resulting from the search for natural kind papers in the 2001-2017 WoS. ${ }^{13}$ Figure 3 shows the visualisation of their author $\mathrm{BC}$ networks. The red cluster consists mostly of philosophers. The green and blue clusters, on the other hand, consist of authors from two research fields in psychology: research on emotion (blue) and categorization (green). The yellow cluster connecting the blue and green clusters consists of authors mostly in neurology or neuropsychology.

This map clearly shows that researchers in other fields too use the notion of natural kinds, and refer to philosophical sources in their work on this topic. In addition, it is worth noting that while psychological work on emotions (blue) and categorization (green) are both well connected to philosophical work on natural kinds, they are not well connected to each other. This suggests that philosophical research on natural kinds (along with work in neuropsychology) acts as a meeting point for these otherwise largely unconnected research fields.

\footnotetext{
${ }^{13}$ See supplementary material, 'term 3 ' for the search term. To make sure that the BC-map is not determined by spurious results (e.g. 'disasters of the non-natural and natural kind'), we randomly checked $10 \%$ of the documents on which the map was based. As none of these were spurious, and because the clusters on the map are clearly relevant to 'natural kinds', it is clear that the shape of this map is not determined by spurious results.
} 


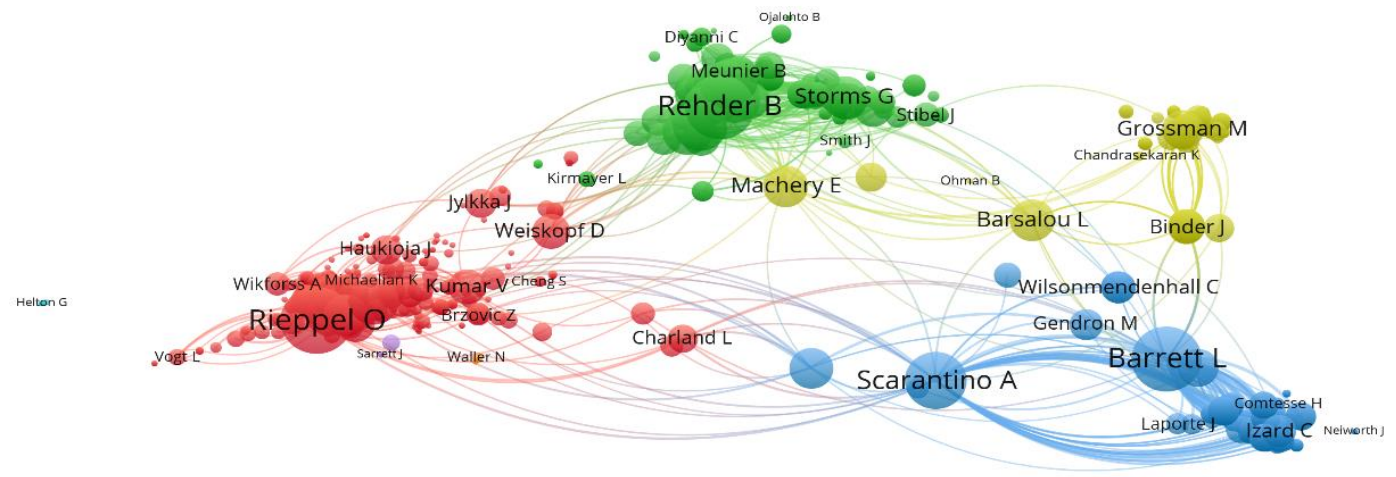

\section{ß vosviewer}

Figure 3. The bibliographic coupling network of $\mathbf{5 7 2}$ authors from papers on natural kinds (2001-

2017). Note: Clustering resolution is 0.7 forming seven clusters. Three clusters including ten authors are singletons in the network.

Again, it will be helpful to compare this map to the equivalent map of a similar but different philosophical concept. As the notion of objectivity, which was compared with natural kinds in the last subsection, is commonly used in a non-technical sense in non-philosophical research, a comparison map of objectivity in WoS would not be meaningful. Instead, we generated a BC map using the 525 papers resulting from a search for papers about 'law of nature' in WoS. ${ }^{14}$ We argue that 'law of nature' is an appropriate term for comparison as it is a strictly philosophical term that has a similar relation to other fields of science as the natural kind concept (both are abstract categories of scientific outcomes). Figure 4 shows a dispersed network of clusters and a relatively integrated centre of strictly philosophical researchers. This shows that while research on laws of nature is relatively integrated within philosophy, it lacks stable connections to other fields of research.

${ }^{14}$ See supplementary material, 'term 4' for the search term. 


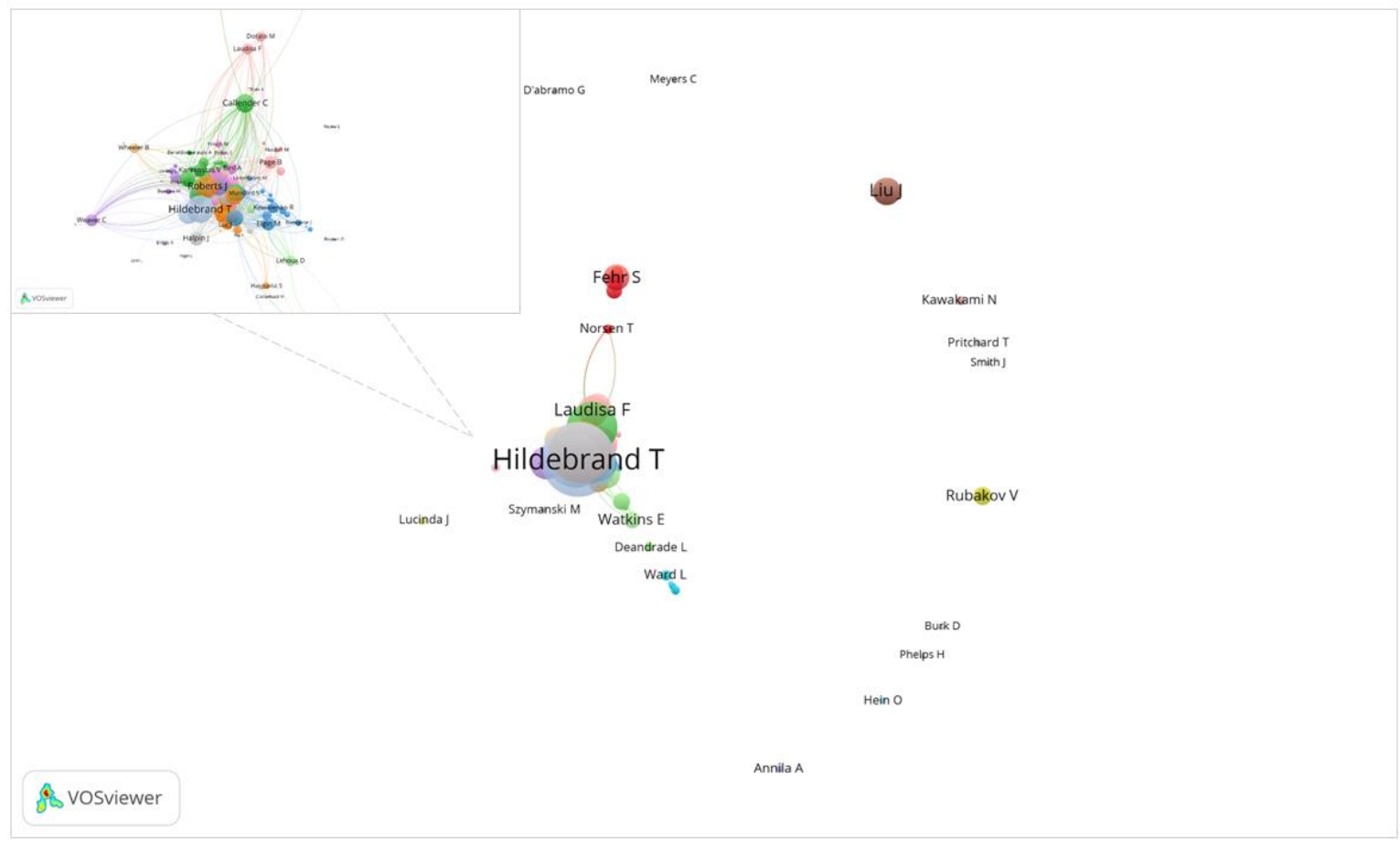

Figure 4. The bibliographic coupling network of $\mathbf{3 0 3}$ authors from papers on laws of nature (20012017). Clustering resolution is 0.9 forming 26 clusters. Six clusters including 14 authors are singletons in the network.

This is confirmed by an analysis of the WoS subject categories of the papers citing all papers about 'natural kind' and 'law of nature' in the eleven philosophy journals discussed in subsection 6.1. Between 2001 and 2017, there were 96 articles on natural kinds in these journals. They were cited by 874 unique articles from 103 different subject fields. This shows that philosophical work on natural kinds does not merely build on work from different disciplines, but also impacts it. As Table 1 shows, about $30 \%$ of the articles citing natural kind papers had a different subject category than 'philosophy', 'history and philosophy of science', or 'ethics'. In the same period and same journals, there were 69 papers about 'law of nature' with 380 citing papers. ${ }^{15}$ These were from only 49 different WoS subject categories, with $98 \%$ of all citations coming from either philosophy, history and philosophy of science, or ethics. In short, it is clear that the phrase 'natural kinds', much more than 'law of nature', forms a connection between philosophers and researchers from other disciplines. As elimination would remove this connection, this constitutes a reason to keep using the phrase.

Table 1. Top 10 WoS subject categories of papers citing natural kind and law of nature papers in philosophy (2001-2017)

\begin{tabular}{|l|r|r|l|r|r|}
\hline \multicolumn{2}{|c|}{ Natural Kind } & \multicolumn{3}{c|}{ Law of Nature } \\
\hline WoS Categories & $\begin{array}{l}\text { No. of } \\
\text { papers }\end{array}$ & $\%$ & WoS Categories & $\begin{array}{l}\text { No. of } \\
\text { papers }\end{array}$ & $\%$ \\
\hline Philosophy & 363 & 43.5 & Philosophy & 228 & 60.0 \\
\hline History Philosophy of Science & 254 & 30.5 & History Philosophy of Science & 142 & 37.4 \\
\hline Psychology Multidisciplinary & 48 & 5.8 & Physics Multidisciplinary & 14 & 3.7 \\
\hline Ethics & 40 & 4.8 & Religion & 9 & 2.4 \\
\hline Psychology Experimental & 38 & 4.6 & Psychology Experimental & 6 & 1.6 \\
\hline Neurosciences & 27 & 3.2 & Psychology Multidisciplinary & 6 & 1.6 \\
\hline
\end{tabular}

\footnotetext{
${ }^{15}$ See supplementary material, 'term 5 ' for the search term.
} 


\begin{tabular}{|l|r|r|l|r|r|} 
Behavioral Sciences & 21 & 2.5 & Ethics & 5 & 1.3 \\
\hline Computer Science Artificial Intelligence & 19 & 2.3 & Economics & 4 & 1.1 \\
\hline Psychology Biological & 16 & 1.9 & Logic & 4 & 1.1 \\
\hline Evolutionary Biology & 15 & 1.8 & Ecology & 3 & 0.8 \\
\hline & & & $\begin{array}{l}\text { Mathematical Computational } \\
\text { Biology }\end{array}$ & 3 & 0.8 \\
\hline & & & Mechanics & 3 & 0.8 \\
\hline
\end{tabular}

However, one might argue that this argument only holds if their work on natural kinds is the only way these researchers are connected to philosophical research. If it turns out that these researchers interact with philosophers even outside of the natural kind debate, the argument no longer holds. Hence, it is important to test how important the phrase 'natural kinds' is in connecting these nonphilosophers to philosophy.

To do this, we investigated what proportion of these authors' references to philosophical papers are references to papers about natural kinds. We collected all non-philosophical papers that cite papers about natural kinds published between 2001 and 2017 in the 11 philosophy journals discussed in subsection 6.1. ${ }^{16}$ We then listed the authors of these non-philosophical papers, and investigated the total number of times each of them cited any paper published in these 11 journals between 2001 and 2017. This allowed us to compare these authors' total number of references to natural kind-papers to their total number of references to philosophical papers, and, thus, measure how important the natural kind debate is in their connection to philosophy. For the 504 authors who published nonphilosophical papers citing natural kind papers, the average proportion of natural kind papers in all their references to philosophical papers is $82.7 \%$. After removing philosophers (defined as authors with a primary affiliation to a philosophy department) from these 504 authors, the proportion further increased to $88.8 \%$. This confirms our hypothesis that the phrase 'natural kinds' plays a crucial role in connecting non-philosophical researchers to philosophical research: if these authors' references to papers about natural kinds are not included, only $11 \%$ of their references to philosophical work remain.

\subsection{Conclusions}

The bibliographic tests confirm our hypothesis that the phrase 'natural kind' ties together a research community. Unlike research on objectivity, natural kind research takes place in a well-integrated philosophical research programme. Unlike research on laws of nature, this research programme is also connected to research outside philosophy. Finally, these connections to non-philosophers turn out to be very much dependent on the this phrase: if their connections to the natural kind research programme were to be removed, most of these non-philosophers would have no other connection with philosophy. Together, these tests suggest that an important social investigative role would be lost if we were to eliminate the phrase 'natural kinds' from philosophy.

\section{When to eliminate investigative concepts}

The previous sections argued that the notion of natural kind facilitates investigation into the cluster of natural kind phenomena. This shows that getting rid of natural kinds will cost more than merely our 'attachment to the traditional label' (Ludwig 2018, p. 47). However, this does not yet establish that the concept should be retained. For this, two additional requirements need to be met. First, any widely

\footnotetext{
16 'Non-philosophical' is defined as any WoS category except for 'Philosophy', 'History Philosophy of Science' and 'Ethics'.
} 
used philosophical or scientific concept, including those that are epistemically harmful, is likely to play some direct and social investigative role (for example, by enabling studies that show that the concept is confused). Thus, it is important to establish that the concept in question plays a useful or productive investigative role. Second, we saw in section 2 that the natural kind concept also harms philosophical investigation. Thus, an anti-eliminativist argument like ours has to establish that the epistemic benefits from the investigative role outweigh these harms. This section argues that both requirements are met in the case of the natural kind concept.

It is difficult to evaluate the epistemic usefulness of investigative concepts. Commonly used criteria like explanatory power, inferential potential or predictive power are all attuned to the evaluation of concepts that play a theoretical role. However, the merits of investigative concepts like genes, innateness or natural kinds are independent from the theoretical role they can play. Thus, even concepts that score badly on traditional epistemic virtues can be productive in an investigative sense. Thus, we suggest it is better to evaluate investigative concepts on the basis of the research they spur and enable: investigative concepts that lie at the basis of good research should be retained; investigate concepts that harm the study of the phenomena of interest should be eliminated.

Given that the evaluation of investigative concepts requires an evaluation of the body of research that they enable, it is helpful to draw a parallel with Lakatos' (1976) views on the equivalent question about research programmes in science. Lakatos distinguishes between progressive and degenerative scientific research programmes. Progressive research programmes are programmes that make new explanations and predictions that are borne out by new data. Research programmes are degenerative when they fail to expand their theoretical scope or only make predictions that remain unconfirmed. Using these notions to discuss researchers' choices of research programmes, Lakatos argues that it is rational for a scientist to abandon a research programme when it is degenerative and, importantly, if there is a progressive alternative available.

Drawing on Lakatos' distinction, we can use similar criteria to investigate whether it would be advisable for philosophers to abandon the concept of natural kinds and the philosophical research programme that is connected to it. As philosophical research typically does not make testable predictions, and thus cannot be borne out by data in the same way as empirical research, Lakatos' criteria need adaptation for these purposes (Nanay 2014). Thus, we might instead ask whether recent work on natural kinds has provided new explanations or understanding of classificatory practice, whether it has successfully been applied to new domains, and whether it has uncovered any new interesting patterns in classificatory practices.

The discussion in section 5 suggests an affirmative answer to these questions: Love (2009) and MacLeod (2013) point to novel roles of natural kinds in science, Bursten (2018) uncovers a novel pattern in the difference between kinds in synthetic and traditional disciplines, Slater (2014) uncovers the common ground between multiple accounts of natural kinds, and further examples are not hard to come by. Ludwig $(2018$, p. 32 ) also seems to think that the field is in a progressive state, as he speaks of the 'recent flourishing' of theories of natural kinds, and MacLeod and Reydon (2013, p. 82) even write about a 'new dawn' of the concept.

Two trends in this research are particularly relevant for highlighting the progressive state of the field. First, unlike much older work on natural kinds, recent work pays careful attention to the role kinds play in scientific practice. This is perhaps exemplified most clearly by a recent collected volume on 'natural kinding', which investigates how kinds are constructed or discovered in scientific practice (Kendig, 2016). Second, philosophers increasingly focus on classificatory practices in disciplines that have traditionally remained below the radar of philosophers of science, such as cognitive science, 
nanoscience, polymer classification and protein classification (Bursten 2018; Havstad 2018; Khalidi 2013; Pöyhönen 2015). The result of these trends is that, far from having 'little to do with issues that arise in a larger context' (Hacking 2007, p. 229), philosophical debates about natural kinds engage with issues that are relevant to scientific practice.

In short, philosophical research on natural kinds seems to be in a progressive state, even if the concept itself plays an investigative rather than a theoretical role. In addition, it is worth noting that it is not clear that there is an alternative concept available that can take over the role of the natural kind phrase and concept. This is important, as Lakatos emphasizes that it is only rational to abandon a research programme if there is a progressive alternative available. Ludwig $(2018$, p. 31) proposes a 'multidimensional framework of non-arbitrary classification', consisting of the various accounts of natural kinds liberated from the general category that collects them. Other authors propose particular accounts of natural classification, such as purely epistemic accounts (e.g. Ereshefsky and Reydon 2014; Franklin-Hall 2015). However, as all these accounts remove the ties between the different kinds of natural kinds, it is unclear how they can play the roles highlighted in this paper. That is, they seem unable to facilitate research on the connection between the different accounts and on at least some of the general patterns across the different accounts. In addition, they would not take over the established social role of the natural kind phrase. Thus, even if these accounts and Ludwig's framework provide promising alternatives for the potential theoretical role of the general natural kind concept, they fail to provide an alternative for its investigative role. Lacking such an alternative, it would be rational for philosophers to stick to the concept even if it were not progressive.

\section{Conclusions}

This paper has argued against natural kind eliminativism by showing that Ludwig's and Hacking's arguments for this position do not hold under scrutiny. More precisely, we have indicated that eliminativism cannot be justified merely by showing that the general concept of natural kinds does not play a theoretical role in debates about non-arbitrary classification. This is because the concept of natural kinds plays a fruitful investigative role in philosophy of science. Given the healthy state of philosophical research on natural kinds, we argue that this gives us good reason to stick to the concept despite its shortcomings.

Our arguments have broader implications for debates about eliminativism and pluralism too. The case of natural kinds suggests that we should thoroughly asses the role a concept plays in a particular research context before calling for elimination. We have argued that even if a philosophical concept plays no theoretical role, it can still contribute to philosophical research through its investigative roles. Other philosophers have pointed to the variety of roles concepts can play in science (Brigandt 2003; Love 2009; MacLeod 2013; Pöyhönen 2013). If we accept the plausible pragmatic view that epistemically useful concepts should be retained in science and philosophy, all these roles should be taken into consideration.

\section{Acknowledgements and author contributions}

We want to thank David Ludwig, Olivier Lemeire and participants of the CLPS Brown Bag Seminar in Leuven for their helpful comments on this paper. Stijn Conix gratefully acknowledges funding from the KU Leuven onderzoeksraad (grant 3H160214) and from the Flemish Research Council (FWO; grant 3H200026). The first draft of the paper was written by Stijn Conix, apart from section 6 , which was written by Pei-Shan Chi. Both authors contributed to the design of the research methodology 
and data collection for the tests in section 6. Pei-Shan Chi performed the analysis and designed the figures. Both authors read and revised multiple drafts of the paper. 


\section{Bibliography}

Bettencourt, L. M. A., Kaiser, D. I., \& Kaur, J. (2009). Scientific discovery and topological transitions in collaboration networks. Journal of Informetrics, 3(3), 210-221.

https://doi.org/10.1016/j.joi.2009.03.001

Betz, G. (2012). Debate Dynamics: How Controversy Improves Our Beliefs. Springer Science \& Business Media.

Borg, A. M., Frey, D., Šešelja, D., \& Straßer, C. (2018). Epistemic Effects of Scientific Interaction: Approaching the Question with an Argumentative Agent-Based Model. Historical Social Research / Historische Sozialforschung, 43(1 (163)), 285-307.

Boyd, R. (1991). Realism, anti-foundationalism and the enthusiasm for natural kinds. Philosophical Studies, 61(1-2), 127-148. https://doi.org/10.1007/BF00385837

Brigandt, I. (2003). Species pluralism does not imply species eliminativism. Philosophy of Science, 70(5), 1305-1316. https://doi.org/10.1086/377409

Bursten, J. R. (2018). Smaller than a Breadbox: Scale and Natural Kinds. The British Journal for the Philosophy of Science, 69(1), 1-23. https://doi.org/10.1093/bjps/axw022

Campbell, J. K., O’Rourke, M., \& Slater, M. H. (2011). Carving Nature at Its Joints: Natural Kinds in Metaphysics and Science. MIT Press.

Cowie, F. (2009). Why isn't Stich an ElimiNativist? In D. Murphy \& M. Bishop (Eds.), Stich and His Critics (pp. 74-100). Wiley-Blackwell.

Dupré, J. (1993). The Disorder of Things: Metaphysical Foundations of the Disunity of Science.

Cambridge, MA: Harvard University Press.

Ereshefsky, M. (1992). Eliminative pluralism. Philosophy of Science, 59(4), 671-690.

Ereshefsky, M., \& Reydon, T. A. C. (2014). Scientific kinds. Philosophical Studies, 172(4), 969-986. https://doi.org/10.1007/s11098-014-0301-4

Franklin-Hall, L. R. (2015). Natural kinds as categorical bottlenecks. Philosophical Studies, 172(4), 925-948. https://doi.org/10.1007/s11098-014-0326-8 
Frey, D., \& Šešelja, D. (2019). Robustness and Idealizations in Agent-Based Models of Scientific Interaction. The British Journal for the Philosophy of Science. https://doi.org/10.1093/bjps/axy039

Frigg, R., \& Hunter, M. (2010). Beyond Mimesis and Convention: Representation in Art and Science. Springer Science \& Business Media.

Glänzel, W., \& Czerwon, H. J. (1996). A new methodological approach to bibliographic coupling and its application to the national, regional and institutional level. Scientometrics, 37(2), 195221. https://doi.org/10.1007/BF02093621

Griffiths, P. E. (2002). What Is Innateness? The Monist, 1(85), 70-85. https://doi.org/10.5840/monist20028518

Hacking, I. (1991). A tradition of natural kinds. Philosophical Studies, 61(1-2), 109-126. https://doi.org/10.1007/BF00385836

Hacking, I. (2007). Natural kinds: Rosy dawn, scholastic twilight. Royal Institute of Philosophy Supplement, 82(61), 203-239.

Hampton, J. (2010). Concept Talk Cannot Be Avoided. Behavioral and Brain Sciences, (33), 212-213. Havstad, J. C. (2018). Messy Chemical Kinds. The British Journal for the Philosophy of Science, 69(3), 719-743. https://doi.org/10.1093/bjps/axw040

Kendig, C. (2016). Natural Kinds and Classification in Scientific Practice. London and New York: Routledge.

Kessler, M. M. (1963). Bibliographic coupling between scientific papers. American Documentation, 14(1), 10-25. https://doi.org/10.1002/asi.5090140103

Khalidi, M. A. (2013). Natural Categories and Human Kinds: Classification in the Natural and Social Sciences. Cambridge, UK: Cambridge University Press.

Khalidi, M. A. (2015). Natural kinds as nodes in causal networks. Synthese, 195(4), 1379-1396. https://doi.org/10.1007/s11229-015-0841-y 
Lakatos, I. (1976). Falsification and the Methodology of Scientific Research Programmes. In S. Hardining (Ed.), Can Theories be Refuted? (pp. 205-259). Dordrecht: Springer. https://doi.org/10.1007/978-94-010-1863-0_14

Larivière, V., Gingras, Y., Sugimoto, C. R., \& Tsou, A. (2015). Team size matters: Collaboration and scientific impact since 1900. Journal of the Association for Information Science and Technology, 66(7), 1323-1332. https://doi.org/10.1002/asi.23266

Larivière, V., Haustein, S., \& Börner, K. (2015). Long-Distance Interdisciplinarity Leads to Higher Scientific Impact. PLOS ONE, 10(3), e0122565. https://doi.org/10.1371/journal.pone.0122565 Lemeire, O. (2018). No purely epistemic theory can account for the naturalness of kinds. Synthese. https://doi.org/10.1007/s11229-018-1806-8

Longino, H. E. (1990). Science as social knowledge: Values and objectivity in scientific inquiry. Princeton, NJ: Princeton University Press.

Love, A. C. (2009). Typology reconfigured: From the metaphysics of essentialism to the epistemology of representation. Acta Biotheoretica, 57(1-2), 51-75. https://doi.org/10.1007/s10441-008$9059-4$

Ludwig, D. (2017). The objectivity of local knowledge. Lessons from ethnobiology. Synthese, 194(12), 4705-4720. https://doi.org/10.1007/s11229-016-1210-1

Ludwig, D. (2018). Letting go of "natural kind". Towards a multidimensional framework of nonarbitrary classification. Philosophy of Science, 85(1), 31-52. https://doi.org/10.1086/694835 Machery, E. (2009). Doing without Concepts. Oxford: Oxford University Press.

MacLeod, M. (2013). Limitations of natural kind talk in the life sciences: Homology and other cases. Biological Theory, 7(2), 109-120. https://doi.org/10.1007/s13752-012-0079-6

MacLeod, M., \& Reydon, T. A. C. (2013). Natural kinds in philosophy and in the life sciences: Scholastic twilight or new dawn? Biological Theory, 7(2), 89-99. https://doi.org/10.1007/s13752-012-0080-0 
- - , eds. (2013b). "Natural kinds in philosophy and in the life sciences: Scholastic twilight or new dawn." Special issue. Biological Theory 7 (2).

Magnus, P. D. (2012). Scientific Enquiry and Natural Kinds. London: Palgrave Macmillan UK.

McFarland, Andrew. 2018. "Causation in the metaphysics of science: Natural kinds." Special issue. Synthese 195 (4).

Nanay, B. (2014). Philosophy of Perception as a Guide to Aesthetics. In G. Currie, M. Kieran, A. Meskin, \& J. Robson (Eds.), Aesthetics and the sciences of mind (p. 101-120). Oxford University Press.

Pöyhönen, H. S. (2013). Natural Kinds and Concept Eliminativism. In V. Karakostas \& D. Dieks (Eds.), EPSA11 Perspectives and Foundational Problems in Philosophy of Science (pp. 167-179). Springer, Cham. https://doi.org/10.1007/978-3-319-01306-0_14

Pöyhönen, H. S. (2015). Memory as a cognitive kind: Brains, remembering dyads, and exograms. Natural Kinds and Classification in Scientific Practice, 145-156.

Rosenstock, S., Bruner, J., \& O'Connor, C. (2017). In Epistemic Networks, Is Less Really More? Philosophy of Science, 84(2), 234-252. https://doi.org/10.1086/690717

Slater, M. H. (2014). Natural kindness. The British Journal for the Philosophy of Science, 66(2), 375411. https://doi.org/10.1093/bjps/axt033

Strohminger, N., \& Moore, B. (2010). Banishing the thought. Behavioral and Brain Sciences, (33), $225-226$.

Taylor, H., \& Vickers, P. (2017). Conceptual fragmentation and the rise of eliminativism. European Journal for Philosophy of Science, 7(1), 17-40. https://doi.org/10.1007/s13194-016-0136-2 Thagard, P. (2006). How to Collaborate: Procedural Knowledge in the Cooperative Development of Science. The Southern Journal of Philosophy, 44(S1), 177-196.

https://doi.org/10.1111/j.2041-6962.2006.tb00038.x 
Wang, J., Veugelers, R., \& Stephan, P. (2017). Bias against novelty in science: A cautionary tale for users of bibliometric indicators. Research Policy, 46(8), 1416-1436.

https://doi.org/10.1016/j.respol.2017.06.006

Waters, C. K. (2006). A pluralist interpretation of gene-centered biology. In S. H. Kellert, H. E. Longino, \& C. K. Waters (Eds.), Scientific Pluralism (pp. 190-214). University of Minnesota Press.

Weingart, S. B. (2015). Finding the History and Philosophy of Science. Erkenntnis, 80(1), 201-213. https://doi.org/10.1007/s10670-014-9621-1

Wiley, E. O. (1981). Phylogenetics: Theory and Practice of Phylogenetic Systematics. New York: John Wiley \& Sons.

Wray, K. B. (2002). The Epistemic Significance of Collaborative Research. Philosophy of Science, 69(1), 150-168. https://doi.org/10.1086/338946

Wray, K. B. (2010). Philosophy of Science: What are the Key Journals in the Field? Erkenntnis, 72(3), 423-430. https://doi.org/10.1007/s10670-010-9214-6

Wuchty, S., Jones, B. F., \& Uzzi, B. (2007). The Increasing Dominance of Teams in Production of Knowledge. Science, 316(5827), 1036-1039. https://doi.org/10.1126/science.1136099

Zollman, K. J. S. (2007). The Communication Structure of Epistemic Communities. Philosophy of Science, 74(5), 574-587. https://doi.org/10.1086/525605

Zollman, K. J. S. (2010). The Epistemic Benefit of Transient Diversity. Erkenntnis, 72(1), 17. https://doi.org/10.1007/s10670-009-9194-6 